\title{
Lusioersily
}

\section{Issues in practice based learning in nursing in the United Kingdom and the Republic of Ireland:Results from a multi professional scoping exercise}

Malik, M., \& McGowan, B. (2007). Issues in practice based learning in nursing in the United Kingdom and the Republic of Ireland:Results from a multi professional scoping exercise. Nurse Education Today, 27(1), 52-59. https://doi.org/10.1016/j.nedt.2006.02.007

Link to publication record in Ulster University Research Portal

\section{Published in:}

Nurse Education Today

Publication Status:

Published (in print/issue): 01/01/2007

DOI:

10.1016/j.nedt.2006.02.007

\section{Document Version}

Publisher's PDF, also known as Version of record

\section{General rights}

Copyright for the publications made accessible via Ulster University's Research Portal is retained by the author(s) and / or other copyright owners and it is a condition of accessing these publications that users recognise and abide by the legal requirements associated with these rights.

\section{Take down policy}

The Research Portal is Ulster University's institutional repository that provides access to Ulster's research outputs. Every effort has been made to ensure that content in the Research Portal does not infringe any person's rights, or applicable UK laws. If you discover content in the Research Portal that you believe breaches copyright or violates any law, please contact pure-support@ulster.ac.uk. 


\title{
Issues in practice based learning in nursing in the United Kingdom and the Republic of Ireland: Results from a multi professional scoping exercise
}

\author{
Maggie Mallik $^{\mathrm{a}, *}$, Brian McGowan ${ }^{\mathrm{b}, 1}$
}

a Head of Learning in Practice, Nottingham Unit, Rushcliffe PCT, Barclays Bank Chambers, Tudor Square, West Bridgford, Nottingham NG2 6BT, United Kingdom

${ }^{\mathrm{b}}$ Lecturer in Nursing, University of Ulster, Jordanstown, Belfast BT37 OQB, United Kingdom

Accepted 21 February 2006

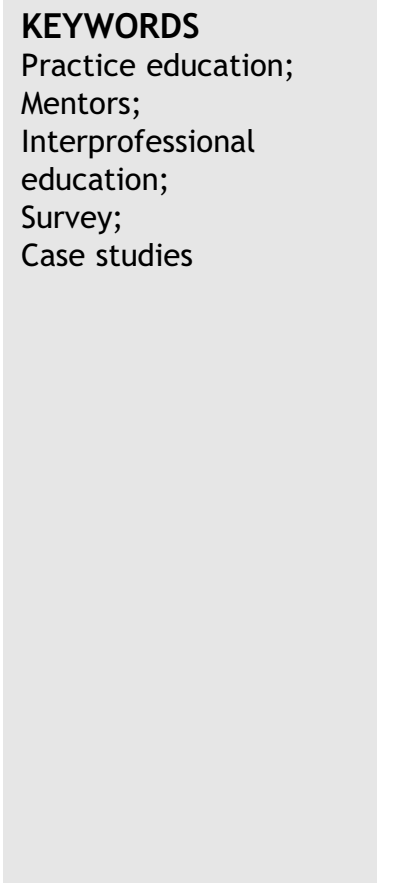

Summary The first year (2003-2004) of a three year nationally funded project focused on completing a scoping exercise on the nature of practice education in five selected health care professions: Dietetics, Nursing, Occupational Therapy, Physiotherapy and Radiography (www.practicebasedlearning.org).

A survey questionnaire, focus groups and secondary sources were used to collect data. Profession specific contributors completed the analysis of results. Resulting case studies were combined to produce a cross-professional overview of current issues in practice-based learning.

The nursing case study identified areas of good practice such as; the mentorship model; the development of new support roles; and joint responsibility between Higher Education Institutes (HEls) and Health Service areas for practice assessment. However, there were variations in the application of these areas of good practice throughout the United Kingdom (UK). Issues included; an inadequate supply of qualified mentors; formal recognition of the mentor role; and lack of knowledge of the relative impact of the differing mentor preparation programmes.

In comparing the five professions, all had statutory requirements regarding the nature of practice learning but each profession differed in how this was managed and organised. The need for formal preparation, recognition and reward for the mentor/practice educator role was recognised with collaborative working across the professions a recommendation in order to achieve national improvement in the quality of practice learning support for health care professions. (c) 2006 Elsevier Ltd. All rights reserved.

\footnotetext{
* Corresponding author. Tel.: +4401159560313.

E-mail addresses: Maggie.mallik@rushcliffe-pct.nhs.uk (M. Mallik), brian.mcgowan@ulster.ac.uk (B. McGowan).

1 Tel.: +440289036 6492 .
} 


\section{Background}

In January 2003, The Department of Employment and Learning (Northern Ireland) and the Higher Education Funding Council for England provided funding for a three year project whose aim was to make practitioners more effective at supporting and supervising students in the workplace across a range of healthcare professions. In particular the project sought to identify and document good practice on preparing practitioners for their educational role; develop and evaluate learning materials for practitioners and disseminate learning materials across health and social care communities.

The first year of the project focused on completing a scoping exercise on the nature of practice education in five selected professions: Dietetics, Nursing, Occupational Therapy, Physiotherapy and Radiography. The professions were selected on the basis of their response to a call to participate (www.practicebasedlearning.org).

A review of the literature informed the design of a questionnaire used to complete the scoping exercise. In keeping with the aims of completing a 'developmental project' rather than systematic research, the review was primarily an appraisal of current issues rather than a systematic review of the literature. The areas covered included the following:

- The nature and effectiveness of practice education.

- Interprofessional learning and practice education.

- Intercultural issues in practice education.

- The role and development of the practice educator (PE).

A full account of the review is not reported here but can be accessed at http: / / www. practicebasedlearning.org/PBL_cs/cont.pdf.

This article provides a summary and discussion of results from the nursing case study (http:// www.practicebasedlearning.org/PBL_cs/nurse.pdf). Comparisons are drawn from the case studies of the other professions. Although some new roles supporting practice learning in nursing have been given the title of 'Practice Educator' (PE) (ENB and DoH, 2001), for the purpose of the project (that included four other professions), a generic definition of PE was accepted by the project team.

In the nursing case study a PE was defined as, "a teacher of nursing, midwifery or health visiting who makes a significant contribution to education in the practice setting, co-ordinating student experiences and assessment of learning. In essence a PE leads the development of practice and provides support and guidance to mentors and others who contribute to the student's experience in practice, enabling them to meet learning outcomes and develop appropriate competencies"'. This was seen to be distinct from a mentor role. However, throughout the literature and for other health and social care professions, practice learning support/education roles are described by a number of terms, including work based supervisor, mentor, preceptor, practice learning facilitator, clinical tutor and trainer. As 'mentor' was the most common term used in nursing and was used exclusively by respondents in the scoping study, it is retained in this article. Where the term practice educator is used to indicate a specific role for the nursing profession it is included with apostrophises, i.e. 'practice educator'.

\section{Methods}

The scoping exercise for each profession was completed by a team from that discipline. Data were collected via questionnaire, focus groups and from secondary sources such as professional bodies, recruitment and $\mathrm{HEl}$ web sites. All HEls offering programmes in the UK and the Republic of Ireland (ROI) were sent questionnaires. Focus group work was undertaken at two sites, Bournemouth and Newcastle where the majority of the teams were based and were open to members of all of the participating professions. The overall aim of using multiple methods for data collection was to broaden the scope of the information obtained rather than providing validation data.

The questionnaire consisted of a series of open and closed questions that provided an overview of current practices. A draft questionnaire was piloted by a convenience sample of six HEI lecturers with an interest in the preparation of practicebased supervisors. Following revisions, the final version of the questionnaire was made available for completion in a number of ways including through an online option. The exercise was carried out between September and November 2003. Data were compiled and analysed from December 2003 to February 2004.

At the time of data collection there were approximately 74 pre-registration nursing programmes listed in the UK (http://www.nursingnetuk.com) and 14 in the ROI $(n=86)$. Table 1 gives the actual number of questionnaires sent and the response 
Table 1 Response rates from all professions

\begin{tabular}{lccl}
\hline Discipline & $\begin{array}{l}\text { Number } \\
\text { sent }\end{array}$ & $\begin{array}{l}\text { Number } \\
\text { returned }\end{array}$ & $\begin{array}{l}\text { Response } \\
\text { rate (\%) }\end{array}$ \\
\hline Dietetics & 13 & 6 & 46.2 \\
Nursing & 86 & 19 & 23.8 \\
Occupational therapy & 31 & 21 & 67.7 \\
Physiotherapy & 37 & 21 & 56.8 \\
Radiography & 26 & 12 & 46.2 \\
Total & 193 & 79 & 40.9 \\
\hline
\end{tabular}

rates for all professions (any omissions reflect difficulties in clarifying course on offer/address/leadership in every listed institution).

Focus groups were conducted at two regional workshops to gather further qualitative data. Robinson (1999) defined focus groups as 'an in-depth, open-ended group discussion that explores a specific set of issues on a pre-defined and limited topic'. From an open invitation to contacts from all the professions involved in the project, participants self-selected themselves by choosing to attend a workshop. At the first workshop, four groups of ten were convened $(N=40)$ and at the second workshop two groups of ten $(N=20)$ contributed their discussion data. Approximately $73 \%$ of attendees were from the nursing profession, thus inevitably forming the majority within each focus group. Questions focussed debate in the following three areas:

1. What is good practice in preparing practitioners for educating students on practice placement?

2. What factors influence the quality of practice education?

3. What materials could be developed to help make practitioners more effective practice educators?

Written records (taken by a member of the project team) of the discussions within each focus group were distributed to each profession's case study team. The accuracy of the notes was verified through more than one member of the project team being present within each of the focus groups.

\section{Ethical considerations}

As a scoping exercise (as opposed to a research study) there were still ethical issues to be taken into consideration. Principally the participants were concerned about confidentiality and the utility of taking part in the project. Respondents were provided with information about the project in advance so that they could decide whether or not they wished to participate. All of the respondents to the questionnaire were assured that their details would remain undisclosed and that the information obtained would be used for the purposes of the project only and not as a process to rank institutions effectiveness at providing mentorship training.

Participants in the focus groups were assured that their identity would not be discoverable from the data recorded and again were given comprehensive background information about the aim of the project and the use to which data would be put to enable them to decide if they wished to take part.

\section{Commentary on results}

It should be noted that the scoping exercise was limited by a poor response $(23 \%)$ to the questionnaire survey. It is suggested that this was perhaps due to the time of year but this time was chosen to offset the problems that would have been encountered if the study had taken place either in the summer or around examination periods. However, nursing was well represented in the focus group work and supported by secondary data obtained through a selection of $\mathrm{HEl}$ web sites throughout the UK. It could be argued that, as respondents/participants were predominantly from the HEls that a further limitation was the lack of input from practice educators and mentors. It was difficult to comment in depth on the results from the ROI survey. Although there were similarities in areas of good practice, e.g. preparation of students for placement learning and the presence of support roles in the health care settings, there are quite distinct differences in the level of preparation offered to practitioners taking on the mentor (known as 'preceptor' in ROI) role.

\section{Areas of good practice}

Areas of good practice included:

- The mentorship model of clinical support.

- The development of new support roles.

- Preparation for the mentor role and continuous updating.

- Joint responsibilities for practice assessment.

- Preparation of students for practice learning.

For nursing the most positive feature of practice learning was the acceptance by experienced practitioners that they should have a key role in the education of pre-registration students. This acceptance 
is historical and arises from the apprenticeship model used in nursing in the UK until the end of the 20th century (Rafferty, 1996). Despite the development of university programmes and the removal of student nurses from the paid workforce in the late 1980s (UKCC, 1985), student supervision continues to be seen as part of every practitioner's role. Comparison with models in use in other countries, where the same process of integration of nurse education into higher education has taken place, testifies to the need to continue with this particular model (Department of Education, Science and Training, 2002; Mallik and Aylott, 2005). Recommendations arising from the UKCC review of nurse education, culminating in the publication of the Peach Report (UKCC, 1999) strengthened the UK mentorship model by recommending strong partnership working between HEls and NHS Trusts.

Additional resources arising from both the recommendations of the Peach Report (1999) and the DoH report 'Making a Difference' (DoH, 1999) has encouraged the development of new support roles, albeit on an 'ad hoc' basis throughout the UK. Although these roles have been variously labelled as Practice Learning Facilitators/Clinical Placement Facilitators/'Practice Educators' and are in the early stages of development and evaluation (Ellis and Hogard, 2003; Clarke et al., 2003), they have the potential to provide structured support for mentors and students; strengthen links between the $\mathrm{HEl}$ and the health service; integrate the theory and practice of nursing; and provide the basis for a clinical academic career structure where practitioners and lecturers could take on interchangeable roles between the health service and the higher education sector. It could be argued that all the benefits arising from this model could be shared and developed across all professional groups in health care in order to provide effective practice based learning.

Retention of the mentor model in nursing has also meant the development of preparation programmes that are a requirement for qualified mentor status. Structured educational preparation was first instigated in the UK with the demise of the Clinical Teacher role in the mid 1980s (ENB, 1989; Mallik and Aston, 2003). Although there has been criticism of the quality of these programmes (Philips et al., 1994; Neary, 1999), they have continued to be provided and accessed by practitioners in order to obtain the qualification necessary to become a mentor. The NMC (NMC, 2004) provides guidance and required standards for mentorship educational programmes (NMC QA Fact Sheet 0/2004) and Practice Educator Programme (NMC QA Fact sheet D7/2004). All HEls providing these programmes must ensure that their educational provision meets NMC standards and outcomes. However, as the NMC advises a flexible approach for the content and process of these programmes, secondary sources for this scoping exercise demonstrates that there is a large variety in the level and number of academic credits awarded for mentor preparation programmes. This ranges from the provision of complete modules of study in some HEls' to one and a half days of in service training. Currently there are no published comparative evaluation studies on the relative effectiveness of these programmes in making practice-based learning work.

The NMC (NMC, 2004) also requires ongoing updates of qualified mentors and an acceptable ratio of mentors to learners (NMC, QA Fact sheet 0/ 2004). Although there is evidence that annual updates are often poorly attended due to staff shortages or for logistical reasons (Pulsford et al., 2002), these standards provide the impetus for good practice and through robust inspection systems can maintain the basis for good quality practice based learning.

Survey data referred to joint assessment of practice learning by practitioners and HEl lecturers. However, there is evidence in the literature of a lack of contact between lecturers and practitioners (Day et al., 1998). Analysis of the focus group data suggested that a shift to a more portfolio based method of assessing practice-learning means that lecturers in partnership with their practice colleagues are more involved in making judgements about the evidence produced by students. Good partnership working is the key to valid and reliable assessment of practice learning and this area of proposed good practice needs more in-depth exploration and development.

Survey, focus group and secondary data confirmed that HEls have systems in place to prepare students for their practice learning experience. These included multiple methods that are well established and also included the development of appropriate online material. Evaluation of the relative impact of different preparation methods needs to be addressed.

\section{Rhetoric versus reality}

All the examples of good practice outlined above, when examined in more depth have the potential to cause problems for practice-based learning. Problems outlined from the survey data need further discussion. These included: 
- Inadequate supply of qualified mentors to meet the increased numbers of students in placement areas.

- Formal recognition and reward for the mentor role.

- Lack of knowledge of the relative impact of the differing mentor preparation programmes highlighted by problems mentors had in dealing with difficult students and in understanding the assessment process and documentation.

Despite considerable resources being expended on facilitating staff to attend mentor preparation programmes and to obtain the qualification, there are still insufficient numbers to meet the ideal $1: 1 / 1: 2$ ratios during placement learning. The use of 'associate mentors' was referred to by the focus group. In practice this term tends to be used to describe qualified nurses who participate in the supervision of nursing students but who are not the named practitioner responsible for assessing competence. However, although there is anecdotal evidence of the continued use of the associate mentor' model throughout the UK, there is a lack of clarity about how these roles are defined, whether any preparation is given and how they impact on the quality of student learning. The NMC guidelines do refer to a flexible approach through the following statement:

'Programme providers should consider how accreditation of prior (experiential) learning might be used to bring all mentors to an equitable level of preparation in meeting the NMC requirements. This would allow those who have undertaken short preparation programmes such as for assessing NVQ/SVQ or developed their competence through experience to reach a comparable standard to those undertaking a contemporary preparation programme'

\section{2)}

(NMC, 2004, QA Fact sheet 0/2004 point 11 page

A recent consultation document (NMC, 2004a) recognised the Associate Mentor role within a developmental framework. The NMC proposed that having associate mentors would recognise stages in the preparation and experience of the role. However, such proposals could produce situations where students are placed in areas where there are insufficient mentors, having a potential negative impact on the quality of practice learning. It could be argued that an associate mentor role would facilitate increased capacity but could fundamentally devalue the complexity and sophistication of the skills required to supervise student nurses by implying that the role can be effectively carried out by those not prepared or trained to do so.

Although there is no formal recognition or pecuniary rewards for undertaking the mentor role, job descriptions for more senior grade posts include the mentor qualification requirement, thus providing an impetus for completing mentor training. Respondents also referred to the amount of time and effort needed to support student learning alongside providing good quality patient care. Many mentors undertake reflection and feedback in their own time and workloads are not reduced to compensate for the extra burden of supporting student learning. Edmond (2001) recognised that given the pressures on clinical staff to provide a service, the quality of learning experienced by each student was akin to a 'lottery' with unpredictable winners and losers. This was identified in the case study as an area that requires urgent attention.

There appeared to be a need for named liaison personnel to act as conduits for communication between practice and HEls. The danger exists that in the absence of such a person, responsibility for mentorship becomes ill defined and 'somebody else's problem'. Solutions proposed by the focus group included:

- Better support from the HEl.

- Specific staff allocated to mentoring activities.

- The development of more placement areas.

The new roles of 'practice educator'/ cclinical placement facilitator' form part of the solution. However, in England, these roles are still being instigated in an 'ad-hoc' way and are subject to local education policy and funding decisions. In the ROI (Department of Health and Children, 2001) and Scotland (http://www.nes.scot.nhs. uk/nursing/), there has been a more integrated approach to the development of these support roles through a strategic commitment to their instigation and development. Mentors' problems around understanding the assessment process and dealing with difficult students could be dealt with through the advice and support from these 'new' post holders.

The quality of preparation programmes for mentors and 'practice educators' was seen as vital and participants felt that preparation should be compulsory with a variety of courses and levels available. Participants saw the mentor role as developmental and suggested that mentors should be learning themselves and receiving supervision/mentoring. In response to a pre-set list of content, the most frequently agreed preparation programme content is listed in Table 2 . The core areas of facilitating 
Table 2 Perceptions of content of mentor preparation courses

\begin{tabular}{ll}
\hline Content & $\begin{array}{l}\text { Frequency in order } \\
\text { of greatest citation }\end{array}$ \\
\hline Roles, responsibilities and & 21 \\
\multicolumn{1}{c}{ accountability of mentor } & \\
Learning contracts & 21 \\
Setting student tasks & 21 \\
Monitoring students progress & 21 \\
Student assessment & 21 \\
Mentoring skills & 21 \\
Coaching skills & 20 \\
Teaching styles & 20 \\
Learning styles & 20 \\
Facilitation of learning & 20 \\
Communication skills & 19 \\
Portfolios & 18 \\
Student absence & 18 \\
Reflective practice & 17 \\
Discipline & 17 \\
Counselling skills & 16 \\
Confidentiality and ethics & 16 \\
Cultural diversity & 16 \\
Programme planning & 15 \\
Consent & 15 \\
Rules and regulations & 15 \\
Report writing & 14 \\
Legal requirements & 14 \\
Health professions council & 14 \\
Mentor/educator absence & 13 \\
Assignment writing & 13 \\
Special needs & 12 \\
Insurance issues & 6 \\
\hline
\end{tabular}

learning, assessment and accountability issues are of prime importance.

Differences occurred between the ROI and the UK in the level and quantity of time spent by practitioners in receiving preparation for their roles as mentors/preceptors, two days preparation in ROI contrasting with the variable lengths of programmes on offer in the UK. In Northern Ireland training is a short one/one and a half days in - service programme; however this situation is currently under review. Each individual $\mathrm{HEI}$ in the UK had their own approach to content, level, length, mode of delivery and audit. As a result the mentorship experience for both mentors and their students varies from place to place. One could argue that this inconsistency leads to confusion and ambiguity and as a result mentorship and indeed practice based learning is compromised. However, there is as yet no comparative empirical data to support any recommendations of the optimum preparation time or programme content.
Diversification also occurred regarding the issue of academic accreditation for any preparation programmes for mentors. Levels of accreditation points awarded appeared to be vague and were not applied with any uniformity across the countries. There is therefore a need to review the actual content and assessment strategies for the undertaking of the generic PE role across all the professional groups. Comparison is essential to set clear standards for the development of interprofessional preparation programmes that will support effective practice based learning.

\section{Comparing professions}

Making comparisons between the five professions involved revealed that there are many common areas of good practice and also areas of difference that give cause for concern to the participating professions. When considering good practice, all the professions reported robust systems in place to prepare students for their practice placements. Focus groups also highlighted good use of Information Technology (IT) facilities to maintain contact and to ensure support for problem solving. Professions were vigilant in ensuring that students met the statutory requirements for practice learning time advocated by their professional regulatory bodies.

All professions claimed to provide their mentors/ PEs with a period of development for their roles. However, the content, length and level varied across and within professions. Only nursing had a statutory requirement that mentors should have completed an accredited level 3 course in order to be qualified to assess students, though this might not be applied uniformly in all countries of the UK, e.g. in Northern Ireland there is currently a relative lack of formal preparation given to mentors to fulfil their roles. The average preparation time across the professions was from 1 day to 3 days and, apart from one example (Physiotherapists and Occupational Therapists who complete a course together at one university), most courses were uniprofessional. All agreed that there was no formal career pathway for mentors/PEs. However, the four professions other than nursing do give pecuniary rewards, though this is currently under review and will be absorbed into the new pay banding structures in Agenda for Change (DoH, 2004).

It was interesting to note that for one profession there was a differentiation between a PE who could assess the student and a 'mentor' who could provide learning support, contributing to teaching and learning only and not summative assessment. All professions agreed that with the current increase 
in commissioning of numbers, there is increased pressure on practice areas to provide placements. Some professions, notably physiotherapy, are seeking to develop new ways of allocating students on $1: 2$ ratios to address this issue http://www. practicebasedlearning.org/PBL_cs/physio.pdf.

\section{Conclusions}

The scoping exercise provided an overview of the current standards for practice based learning in pre-registration nursing programmes in the UK and the ROI. This article presents the results from a national survey of HEl staff in all the countries of the UK and the ROI. Secondary data and data from focus groups were assimilated into the results and the discussion. Overall broadly similar approaches to practice based learning were adopted by all five professions involved in the project. Practitioners providing direct patient/client care hold the key responsibility for facilitating practice learning and assessing the student as competent to register.

In nursing, new partnership practice education supporting roles have being instigated and developed in the UK (clinical placement facilitators) and more particularly in the ROI (clinical placement coordinators). Standards for the preparation, monitoring and development of these post-holders have been developed, but their positions and impact are in the early stages of being evaluated and at a policy level there is still no firm commitment to their ongoing funding particularly in the UK.

From the nursing case study the following profession specific recommendations were made arising out of the key issues identified as problematic:

- Academic and professional accreditation for the status of the mentor is required.

- Employers should acknowledge and reward the demands of a practice education role in relation to clinical workloads.

- Mentorship principles should be introduced in the third year of pre-registration programmes to foster understanding prior to registration.

- A standard developmental model of practice education should be introduced that clarifies a practice education career pathway, e.g. associate mentor to mentor to 'practice educator'.

- Standardisation and evaluation of preparation programmes at appropriate levels to suit an interprofessional practice education career framework.
- Clarification of practice education responsibilities for HEls and placement providers.

The commitment of staff and the organisations involved in the provision and support of practice education for nursing students is evident. It could be argued that whilst areas of good practice exist, these do so despite a number of structures that appear to work against the provision of well-supported, clearly supervised and adequately qualityassured practice education. Some of these problems are within the gift of the professional bodies, the HEls and the placement providers to address and indeed some initiatives are evident (NMC, 2005). Others are related to inadequate funding and require political action from within the profession itself.

Although project work to develop shared resources is ongoing (www.practicebasedlearning.org) there is still a need to address how political action by the professions can be strengthened in order to achieve results. In the final analysis, it could be argued that strength to influence government agendas and implement change can be gained through working collaboratively with other health care professions in addressing the issues that are common to all, working out solutions and developing new ideas to make practice based learning work.

\section{Acknowledgements}

To the funding bodies of the FDTL phase four project 'Making Practice Based Learning Work' and the project team from University of Ulster, Bournemouth University and University of Northumbria.

\section{References}

Clarke, C.L., Gibb, C.E., Ramprogus, V., 2003. Clinical learning environments: an evaluation of an innovative role to support pre-registration nursing placements. Learning in Health and Social Care 2 (2), 105-115.

Day, C., Fraser, D., Mallik, M., 1998. The Role of the Nurse Teacher/Lecturer in Practice. Researching Professional Education No. 8. English National Board, London.

Department of Education, Science and Training, 2002. National Review of Nursing Education: Our Duty of Care. Department of Education, Science and Training, Canberra.

Department of Health, 1999. Making a Difference: Strengthening the Nursing, Midwifery and Health Visiting Contribution in Health and Healthcare. Department of Health, London.

Department of Health, 2004. The NHS Knowledge and Skills Framework (NHS KSF) and the Development Review Process. DoH, London (October 2004). 
Department of Health and Children, 2001. National Evaluation of the Role of the Clinical Placement Co-ordinator. Department of Health and Children, Dublin.

Edmond, C.B., 2001. A new paradigm for practice education. Nurse Education Today 21 (4), 251-259.

Ellis, R., Hogard, E., 2003. Two deficits and a solution? Explicating and evaluating clinical facilitation using consultative methods and multiple stakeholder perspectives. Learning in Health and Social Care 2 (2), 1827.

English National Board and Department of Health, 2001. Preparation of Mentors and Teachers - a new framework of guidance. ENB \& DOH, London.

English National Board for Nursing, Midwifery and Health visiting, 1989. Preparation of Teachers, Practitioners, Mentors and Supervisors in the context of Project 2000. ENB, London.

Mallik, M., Aylott, E., 2005. Facilitating practice learning in preregistration nursing programmes: a comparative review of the Bournemouth collaborative model and Australian models. Nurse Education in Practice 5, 152-160.

Mallik, M., Aston, L., 2003. Providing educator support for practice learning. In: Glen, S., Parker, P. (Eds.), Supporting Learning in Nursing Practice: A Guide for Practitioners. Palgrave Macmillan, London.

Neary, M., 1999. Preparing assessors for continuous assessment. Nursing Standard 13 (18), 41-47.
Nursing and Midwifery Council, 2004. NMC Requirements for Mentors and Mentorship. QA Factsheet 0/2004 ENG. NMC, London.

Nursing and Midwifery Council, 2004a. Consultation on a standard to support practice learning. NMC, London. Available from: <http://www.nmc-uk.org/nmc/main/consultation/ Consultation_on_a_standard>.

Nursing and Midwifery Council, 2005. Consultation on proposals arising from a review of fitness for practice at the point of registration. NMC, London. December 2005.

Philips, T., Schostak, J., Bedford, H., Robinson, J., 1994. Assessment of Competencies in Nursing and Midwifery Education and Training ACE Project. ENB, London.

Pulsford, D., Boit, K., Owen, S., 2002. Are mentors ready to make a difference? A survey of mentors' attitudes towards nurse education. Nurse Education Today 22 (6), 439-446.

Rafferty, A.M., 1996. The Politics of Nursing Knowledge. Routledge, London.

Robinson, N., 1999. The use of focus group methodology - with selected examples from sexual health research. Journal of Advanced Nursing 29 (4), 905-913.

United Kingdom Central Council for Nursing, Midwifery and Health Visiting, 1985. A New Preparation for Practice. UKCC, London.

United Kingdom Central Council for Nursing, Midwifery and Health Visiting, 1999. Fitness for Practice. The UKCCs Commission for Nursing and Midwifery Education (The Peach Report). UKCC, London.

Available online at www.sciencedirect.com

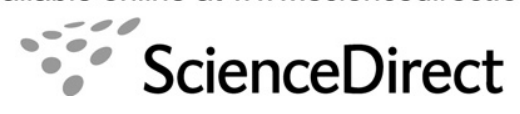

